University of Nebraska - Lincoln

DigitalCommons@University of Nebraska - Lincoln

Court Review: The Journal of the American

Judges Association

American Judges Association

2009

\title{
Judges' Perspectives on Stress and Safety in the Courtroom: An Exploratory Study
}

\author{
David M. Flores \\ University of Nevada - Reno \\ Monica K. Miller \\ University of Nevada - Reno, mkmiller@unr.edu \\ Jared Chamberlain \\ Argosy University - Phoenix Campus \\ James T. Richardson \\ University of Nevada - Reno, jtr@unr.edu \\ Brian H. Bornstein \\ University of Nebraska-Lincoln, bbornstein2@unl.edu
}

Follow this and additional works at: https://digitalcommons.unl.edu/ajacourtreview

Flores, David M.; Miller, Monica K.; Chamberlain, Jared; Richardson, James T.; and Bornstein, Brian H., "Judges' Perspectives on Stress and Safety in the Courtroom: An Exploratory Study" (2009). Court Review: The Journal of the American Judges Association. 293.

https://digitalcommons.unl.edu/ajacourtreview/293

This Article is brought to you for free and open access by the American Judges Association at DigitalCommons@University of Nebraska - Lincoln. It has been accepted for inclusion in Court Review: The Journal of the American Judges Association by an authorized administrator of DigitalCommons@University of Nebraska -

Lincoln. 


\section{Judges' Perspectives on Stress and Safety in the Courtroom: An Exploratory Study}

David M. Flores, Monica K. Miller, Jared Chamberlain, James T. Richardson, \& Brian H. Bornstein

$\mathbf{T}$ he courtroom represents a critical component of the American justice system. The legal system asks judges and juries to deliver justice for injured parties through the cases that they decide. The assumption is that these legal decision-makers can perform these tasks rationally and fairly. This is not always an easy task, however, as the process can expose judges and jurors to a number of stressors that can have negative consequences for both the individuals and the legal system as a whole. First, some trials contain graphic evidence regarding crimes and personal injuries. Judges and jurors are captive audiences and have no choice about viewing photographs and hearing testimony concerning such violent crimes as murder, abuse, and rape. Second, the safety of both judges and jurors can sometimes be compromised during trial. For instance, a defendant in a recent trial in Boston punched a juror, leading the judge to declare a mistrial. During the defendant's second trial, the defendant threatened to kill the jurors. ${ }^{1}$ Judges also have safety concerns: a judge in New York barely avoided being shot when a former defendant fired a sawed off rifle in the courtroom. ${ }^{2}$ Other judges have been threatened, ${ }^{3}$ injured, ${ }^{4}$ or killed ${ }^{5}$ while on the job. Some judges have also experienced violence outside of the courtroom; for instance, in 2005, a man killed U.S. District Judge Joan Lefkow's husband and mother as an act of retribution for her rulings. ${ }^{6}$

Stress and safety concerns have the potential to affect judges' and jurors' performances. For instance, jurors selected for a trial involving a violent crime may experience strong emotions that make it difficult to follow the jury instructions. Judges could also let emotions affect their sentencing judgments or prevent them from making proper decisions (e.g., about impermissible testimony). ${ }^{7}$ Fear of retribution could affect the decisions of both judges and jurors, for example, in gang-related cases. Because stress has the potential to negatively impact the judicial system, researchers have begun to study courtroom stress. ${ }^{8}$ The majority of research concerns juror stress,${ }^{9}$ although several studies have examined judicial stress or judges' perceptions of their safety. 10

The present research is designed to expand on previous research by asking research questions concerning five related areas. First, are judges concerned about juror stress? To the
Authors' Note: The authors would like to thank Ashley Dolezilek, the National Judicial College, and the National Council for Juvenile and Family Court Judges for their assistance with this project. This research was partially funded by the American Psychology-Law Society. Contact the authors through David Flores (dflores@unr.edu).

\section{Footnotes}

1. Associated Press, Man Who Hit Juror in First Trial Threatens Panel during Retrial, BostonGlobe.com, May 30, 2007. http://www. boston.com/news/local/massachusetts/articles/2007 /05/30/man_who_hit_juror_in_first_trial_threatens_panel_ during_retrial/.

2. Associated Press, Judge Nearly Shot in Courtroom, msnbc.com, May 8, 2007, http://www.msnbc.msn.com/id/18559142/.

3. Bill Mears, Justice Ginsburg Details Death Threat, CNN.COM, March, 15, 2006, http://www.cnn.com/2006/LAW/03/15/ scotus.threat/.

4. Associated Press, Judge Shot, Wounded at Nevada Courthouse, USATODAY.COM, June 13, 2006, http://www.usatoday.com/ news/nation/2006-06-12-judge_x.htm.

5. Associated Press, Nichols Wanted to Be with His Baby Boy, FOXNEWS.COM, March, 16, 2005, http://www.foxnews.com/ story/0,2933,150683,00.html.

6. Jeff Coen \& David Heinzmann, Suicide, Double-Murder Linked, CHI. TRIB., March 11, 2005, available at http://www.ocregister .com/ocr/2005/03/11/sections/nation_world/nation_world/ article_438555.php.

7. Jared Chamberlain \& Monica K. Miller, Stress in the Courtroom: A Call for Research (Sept. 19, 2007) (unpublished manuscript, on file with the author) [hereinafter Chamberlain, Call for Research].
8. For a review, see Monica K. Miller \& Brian H. Bornstein, Juror Stress: Causes and Interventions, 30 T. MARSHALl L. Rev. 237 (2004) [hereinafter Miller, Causes and Interventions]; Monica K. Miller, \& David M. Flores. Addressing the Problem of Courtroom Stress, 91 Judicature 60 (Sept./Oct. 2007) [hereinafter, Miller, Courtroom Stress].

9. E.g., Brian H. Bornstein, Monica K. Miller, Robert J. Nemeth, Gregory L. Page, \& Sarah Musil, Juror Reactions to Jury Duty: Perceptions of the System and Potential Stressors, 23 BEHAV. SCI. \& L. 231 (2005) [hereinafter Bornstein, Juror Reactions]; Theodore B. Feldmann \& Roger A. Bell, Crisis Debriefing of a Jury After a Murder Trial, 42 Hospital \& Community Psychiatry 79 (1991) [hereinafter Feldmann, Crisis Debriefing]; Roger A. Bell \& Theodore B. Feldmann, Crisis Debriefing of Juries: A Follow-Up, 4 Am. J. Preventative Psychiatry 2 (1992) [hereinafter Bell, Crisis Debriefing Follow-Up]; Thomas L. Hafemeister \& W. Larry Ventis, Juror Stress: What Burden Have We Placed on Our Juries?, 16 Sт. Ст. J. 35 (1992) [hereinafter Hafemeister, Juror Stress]; National Center for State Courts, Through the Eyes of THE Juror: A MANUAL FOR AdDRESSING JUROR STRESS 1 (1998 ed.)[hereinafter NCSC, 1998 Manual].

10. Donald J. Harris, Charlotte L. Kirschner, Kristina Klatt Rozek, \& Neil Alan Weiner, Violence in the Judicial Workplace: One State's Experience, Annals AM. ACAD. 38, (2001) [hereinafter, Harris, Judicial Workplace]; Peter G. Jaffe, Claire V. Crooks, Billie L. Dunford-Jackson \& Michael Town, Vicarious Trauma in Judges: The Personal Challenge of Dispensing Justice, Juv. \& FAM. CT. J. 1 (2003) [hereinafter Jaffe, Vicarious Trauma in Judges]. 
degree that they are, what steps are they taking to protect jurors? Second, how do judges experience stress personally? What experiences are most stressful and how do judges cope? Third, how do judges feel about personal safety, and what do they do to protect themselves and their families? Fourth, is there a relationship between judges' perceptions of safety and their experiences of stress? Finally, are there differences in judges' perceptions? Specifically does one gender experience greater stress than the other? Do judges who have experienced a stressful work event (e.g., a threat) have different perceptions from those who have not? By answering these important questions, the current exploratory research can help determine what steps can be taken to protect judges and jurors from excessive stress that can impede their performance.

\section{STRESS IN THE COURTROOM}

A number of researchers have studied the stress that judges and jurors experience. ${ }^{11}$ These studies (reviewed below) have determined that jurors do experience stress as a result of a variety of stressors. As a result, some courts have taken measures (e.g., posttrial debriefings) to protect jurors. ${ }^{12}$ Somewhat less attention has been given to the study of judicial stress and safety, although there is some evidence that judges also experience negative effects associated with their duties. ${ }^{13}$ A review of the literature in both areas provides a foundation for the current study.

Evidence of juror stress. Serving as a juror can be difficult or stressful for a variety of reasons. Some of these stressors are fairly obvious, such as deciding on a verdict/sentence, being involved in heated jury deliberations, and hearing about violent or gruesome crimes. ${ }^{14}$ In highly sensationalized cases involving "notorious" defendants (e.g., O.J. Simpson, Martha Stewart), there can also be stress due to intense media scrutiny and/or sequestration. ${ }^{15}$ Less obvious and more mundane stressors occur in more run-of-the-mill cases as well. For example, Bornstein and colleagues $^{16}$ found that in a sample of mostly routine cases, stress levels were relatively low overall. Nonetheless, jurors still reported experiencing some stress associated with the experience. The most stressful elements of jury duty involved: trial complexity (e.g., difficulty understanding the law or testimony), the decision-making process (e.g., having limited input), and disruption to daily life (e.g., long days in court). Although courts can do relatively little about some of these concerns (e.g., the nature of the crime or the necessity of reaching a verdict), others can be addressed by procedural reforms, such as allowing jurors to ask questions, modifying judge's instructions, and providing more frequent breaks. ${ }^{17}$

Several studies have documented significant, albeit subclinical, stress reactions among jurors, especially in cases involving gruesome testimony, high media interest, or severe penalties for defendants. ${ }^{18}$ Documented stress symptoms among jurors include anxiety, sleeplessness, headaches, hives, and high blood pressure. ${ }^{19}$ Very few studies have examined the duration of juror stress posttrial; those few studies indicate that symptoms can last for several months after trial, ${ }^{20}$ though they do abate somewhat. ${ }^{21}$

Courts have a number of tools available to reduce juror stress, which can be implemented at various stages of the process. ${ }^{22}$ For example, courts can (1) inoculate jurors against stress through pretrial orientation; (2) lessen stress during trial by reducing complexity and being more sensitive to jurors' routine needs (e.g., work schedules); and (3) address stress posttrial through debriefings. There is little systematic research on debriefing's effectiveness, but jurors do tend to perceive it as helpful. ${ }^{23}$

Judges can be highly involved in all of these stress-reduction methods, especially those occurring during and after trial. 24 There are a number of practical issues surrounding interventions designed to reduce juror stress, such as who pays for them, who conducts them, etc. ${ }^{25}$ For example, posttrial debriefings can be conducted by either the judge (or other court personnel) or a mental-health professional. The National Center for State Courts (NCSC) study found that judges themselves perceived debriefings led by judges as more beneficial than those led by mental-health professionals. ${ }^{26}$ Although no
11. For a review, see Miller, Causes and Interventions, supra note 8; Miller, Courtroom Stress, supra note 8.

12. Bell, Crisis Debriefing Follow-Up, supra note 9; Feldmann, Crisis Debriefing, supra note 9; Hafemeister, Juror Stress, supra note 9; National Center for State Courts, KIng COUnTy Superior Court: Evaluation of the Jury Debriefing Program: Final Report 1 (2000) [hereinafter, NCSC, Jury Debriefing].

13. Jared Chamberlain \& Monica K. Miller, Evidence of Secondary Traumatic Stress, Safety Concerns, and Burnout Among a Homogeneous Group of Judges in a Single Jurisdiction, 37 J. Aм. AcAd. Psychiatry \& L. 214 (2009) [hereinafter, Chamberlain, Stress Triad]; Jaffe, Vicarious Trauma in Judges, supra note 10; Monica K. Miller, Using Constructivist Self-Development Theory to Explain Judges' Reactions to the Shooting of a Colleague, (Sept. 19, 2007) (unpublished manuscript, on file with the author) [hereinafter, Miller, Judges' Reactions].

14. NCSC, 1998 Manual, supra note 9, at 30.

15. See generally, Timothy R. Murphy, Genevara K. Loveland \& G. Thomas Munsterman, Managing Notorious Cases (1992).

16. Bornstein, Juror Reactions, supra note 9, at 331.

17. Miller, Causes and Interventions, supra note 8, at 262.
18. Feldmann, Crisis Debriefing, supra note 9, at 80; Theodore B. Feldmannn \& Roger A. Bell, Juror Stress: Identification and Intervention, 21 Bull. AM. ACAD. Psychiatry L., 409, 412 (1993); Stanley M. Kaplan, \& Carolyn Winget, The Occupational Hazards of Jury Duty, 20 Bull. Am. ACad. Psychiatry L. 325, 327 (1992) [hereinafter, Kaplan, Occupational Hazards]; James E. Kelley, Addressing Juror Stress: A Trial Judge's Perspective, 43 DraKe L. REV. 97 (1994) [hereinafter Kelley, Judge Perspective]; Daniel W. Shuman, Jean A. Hamilton \& Cynthia E. Daley, The Health Effects of Jury Service, 18 Law \& Psychol. Rev. 267, 290 (1994) [hereinafter Shuman, Health Effects].

19. Kaplan, Occupational Hazards, supra note 18, at 328.

20. Bell, Crisis Debriefing Follow-Up, supra note 9, at 4; Shuman, Health Effects, supra note 18, at 295.

21. Bornstein, Juror Reactions, supra note 9, at 333.

22. Miller, Causes and Interventions, supra note 8, at 246.

23. Bornstein, Juror Reactions, supra note 9, at 334.

24. See generally, NCSC, 1998 Manual, supra note 9; NCSC, Jury Debriefing, supra note 12.

25. Miller, Causes and Interventions, supra note 8, at 252.

26. NCSC, 1998 Manual, supra note 9, at 83. 
study has assessed the effectiveness of debriefing as a function of who conducts it, it is certainly plausible that judges would be more effective, by virtue of their authority and having lived through the same experience as jurors; nonetheless, this approach begs the question: Who debriefs the judge?

Evidence of judicial stress. Judges experience a number of stressors, such as substantial workloads, traumatic cases, pressure of making significant decisions, and safety concerns. ${ }^{27}$ As a result, judges can experience stress symptoms such as sleep disturbances, intolerance of others, depression, and isolation. ${ }^{28}$ The NCSC study found that $50 \%$ of judges report experiencing high levels of stress during a trial. ${ }^{29}$ Although this question was quite general, other studies and theoretical models have investigated more specific aspects of judicial stress.

Miller and Richardson ${ }^{30}$ propose a model suggesting that stress can have a number of causes and consequences. The model predicts that a variety of factors can cause stress and safety concerns, which in turn can then lead to various outcomes. The model suggests three types of factors that can cause stress and safety concerns: Personal (e.g., gender), job (e.g., high number of stressful trials), and environmental characteristics (e.g., awareness of violent acts against other judges). The model suggests that some of these characteristics have a direct effect on stress; however, they may also affect stress indirectly. Specifically, a factor can affect safety concerns, which in turn lead to stress. Stress can lead to a variety of outcomes, including problems with health, personal relationships, and job performance.

This model is based on previous research with other groups (e.g., counselors, emergency medical personnel), and relies on previous studies researching secondary traumatic stress, workrelated burnout, vicarious trauma, and Constructivist SelfDevelopment Theory. ${ }^{31}$ Although the model itself has yet to be tested, other research supports its basic propositions. For instance, Chamberlain and Miller ${ }^{32}$ conducted interviews and found that judges experience vicarious trauma, resulting from witnessing victimization of others. ${ }^{33}$ Jaffe and colleagues ${ }^{34}$ also found support for the notion that judges experience vicarious trauma; $63 \%$ of the 105 judges included in the study reported experiencing at least one symptom of vicarious trauma. Judges who play the role of caretaker (e.g., deciding whether a child should remain with parents) are especially likely to experience vicarious trauma due to witnessing the traumas experienced by the individuals under the judge's care.

As a result of their work experiences, judges can also face unfavorable effects as predicted by Constructivist SelfDevelopment Theory (CSDT). Applied to judges, CSDT would posit that trauma affects a judge's psychological needs; these needs are related to the individual's sense of safety, trust, esteem, independence, power, and intimacy. ${ }^{35}$ If these needs are unmet, the judge's view of the world and the self will change. Miller ${ }^{36}$ found at least moderate evidence that judges who had experienced a traumatic event had also experienced symptoms in accord with CSDT. Occupational burnout is also a risk for judges. Judges report difficulty making decisions, work blocks, and negative feelings about their profession, ${ }^{37}$ which could indicate work-related burnout. Judges also experience a variety of other symptoms associated with burnout. ${ }^{38}$

Judges experience a variety of safety issues as well. Harris and colleagues ${ }^{39}$ surveyed judges about their experiences with work-related safety issues. Over half (52\%) of the 1,112 judges questioned had been threatened in some way. Seventy percent of these incidents occurred outside the courthouse, indicating that threatening situations are not limited to the workplace. Fifty-eight percent of judges felt it was necessary to change their behavior in light of these threats. Similarly, Chamberlain and Miller ${ }^{40}$ found that many judges had significant concerns for their safety, both in and out of the courthouse.

Finally, there is evidence that judges are sensitive to jurors' stress. ${ }^{41}$ A national survey of judges indicated that most believe that jurors typically experience low to moderate stress levels. Nevertheless, $29 \%$ of judges felt that stress affects the ability of at least some jurors. Additionally, $65 \%$ of judges believe that people avoid jury duty because they fear stress, and $77 \%$ had excused a potential or actual juror because of the juror was experiencing or would likely experience stress. Nearly all (97\%) judges said that they believed courts have a responsibility to prevent, address, or minimize stress; $78 \%$ said they had used at least one strategy to do so. The most common strategies were (1) attempting to maintain a positive rapport with jurors, (2) explaining the trial process to jurors before trial, (3) limiting delays, (4) asking jurors their wishes about lunchtime, etc., and (5) instructing court officials to be sensitive to juror needs.
27. Chamberlain, Stress Triad, supra note 13.

28. Jaffe, Vicarious Trauma in Judges, supra note 10, at 5.

29. National Center for State Courts, Through the Eyes of the Juror: A Manual for Addressing Juror Stress 20 (2002 ed.), available at http://www.ncsconline.org/WC/Publications/Res_Juries_JurorStre ssIndexPub.pdf [hereinafter, NCSC, 2002 Manual].

30. Monica K. Miller \& James T. Richardson, A Model of Causes and Effects of Judicial Stress, 45 JudGES' J. 20 (2006).

31. Karen W. Saakvitne, Howard Tennen \& Glenn Affleck, Exploring Thriving in the Context of Clinical Trauma Theory: Constructivist Self-Development Theory, 54 J. Soc. Issues 279. (1998) [hereinafter, Saakvitne, Constructivist Self-Development Theory].

32. Chamberlain, Stress Triad, supra note 10.

33. See Laurie A. Pearlman \& Paula S. MacIan, Vicarious Traumatization: An Empirical Study of the Effects of Trauma on Trauma Therapists, 26 Prof. Pshchol., Res. \& Practice 558 (1995).
34. Jaffe, Vicarious Trauma in Judges, supra note 10, at 4.

35. Saakvitne, Constructivist Self-Development Theory, supra note 31, at 293.

36. Miller, Judges' Reactions, supra note 13,

37. Tracy D. Eells \& Robert Showalter, Work-Related Stress in American Trial Judges, 22 Bull. Am. AcaD. Psychiatry \& L. 71, 74 (1994)

38. E.g., overload of responsibility, workplace conflict, see Chamberlain, Stress Triad, supra note 13.

39. Harris, Judicial Workplace, supra note 10.

40. Chamberlain, Stress Triad, supra note 13.

41. NCSC, 2002 Manual, supra note 29, at 3. 
To date, there is considerably more research concerning jurors' stress than judges' stress. ${ }^{42}$ This is a concern because judges have to deal with more potentially stressful evidence than jurors as they have to determine the admissibility of evidence that jurors might not see (e.g., gruesome evidence). ${ }^{43}$ In addition, judges have to deal with such hassles daily, while jurors experience such trials very infrequently. Frequent experiences with such stressors could be detrimental and could lead to mental-health issues (e.g., vicarious trauma) or desensitization. Just as with jurors, some of the stressors that affect judges are obvious and hard to remediate (e.g., presiding over cases with disturbing evidence, sentencing in capital cases), while others are more mundane and more amenable to remediation (e.g., workload, lack of training/preparation ${ }^{44}$ ).

As Chamberlain \& Miller ${ }^{45}$ point out, more research is needed to understand judges' experiences with stress. The literature on jury and judge safety and stress has some limitations. The first concern this exploratory study addresses is the limited scope of previous studies. While previous studies concerning judicial stress ${ }^{46}$ investigate very specific types of stressors or symptoms (e.g., vicarious trauma, occupational burnout, Constructivist Self-Development Theory), the current study is much broader in scope. Second, the current study expands on previous research by using more formal measures of stress, depression and anxiety. Shuman and colleagues ${ }^{47}$ and Bornstein and colleagues ${ }^{48}$ used clinical measures (e.g., scales measuring Post-Traumatic Stress Disorder, depression, and anxiety) with jurors, but these measures have yet to be used with judges. Third, the current study fills a gap in the research by identifying differences based on individual factors. That is, does gender, experience with a work-related stressful issue (e.g., violence), or the type of cases a judge typically handles affect his/her perceptions and behaviors? In addition, the current study links stress and safety to determine the relationship between the variables. Finally, not much is known about what steps judges take to address their safety and stress needs or the needs of jurors. This is important, yet largely unknown, information that can help courts protect these legal decision makers.

In an effort to address this void, this exploratory study surveyed judges to gather tentative evidence on five major research questions:

Research Question 1: How do judges feel about juror stress? What have they done to protect jurors?

Research Question 2: How do judges experience stress personally? What aspects of their occupational duties are most stressful, and how do they cope?

Research Question 3: How do judges feel about personal safety? What do they do to protect themselves and their families?
Research Question 4: Is there a relationship between judges' perceptions of safety and their experiences of stress?

Research Question 5: Are there differences in experiences of stress or perceptions of safety with respect to gender, the type of cases that the judge typically presides over, or the experience of a workplace safety issue?

\section{METHOD \\ Participants}

A convenience sample of 163 American trial judges participated in the current study. The responders included 95 (58\%) males, 65 (40\%) females, and 3 (2\%) who chose not to indicate gender. Sixty-six (40.2\%) indicated they had experienced a "work-related stress/safety incident," answering affirmatively to the question "In the past year, did you experience any workrelated event that caused you stress (e.g., a violent or threatening event)?"

When asked what type of trial they typically presided over, 35 respondents (21\%) indicated civil trials, 21 (12\%) criminal, 74 (45\%) both, and 33 (20\%) responded "Other." The respondents included 67 (41\%) from general jurisdiction courts, 48 (29\%) from family courts, 46 (28\%) from state supreme courts, and $2(1 \%)$ from appellate courts. Analyses revealed no significant differences with respect to the type of trial a judge typically presided over or the classification of judge. As a consequence, these distinctions are omitted from the discussion of results.

\section{Procedure}

Participants were affiliated with either the University of Nevada Reno Judicial Studies graduate program for trial judges or the National Council of Juvenile and Family Court Judges (NCJFCJ). Prospective participants were sent an email requesting their participation in a study about the causes and implications of judicial stress. The correspondence included a brief description of the study and a link to a secure online survey site that hosted the survey.

\section{Materials}

The online survey consisted of 167 items, which took participants approximately 30-45 minutes to complete. In order to address the individual research questions, numerous instrument items targeted respondents' perceptions of jury stress and judges' own experiences with stress and safety issues (a more detailed discussion of which is included in the foregoing analyses). In an effort to build upon previous research, the instrument also included several clinical measures for use as dependant variables, including the Center for Epidemiology Studies Depression Scale, ${ }^{49}$ a brief form of the Speilberger State
42. For a review, see Miller, Courtroom Stress, supra note 8; Miller, Causes and Interventions, supra note 8.

43. Brian H. Bornstein \& Robert J. Nemeth, Jurors' Perception of Violence: A Framework for Inquiry, 4 AgGRESSION \& ViOlent BeHAV. 77, 78 (1999).

44. See Celeste F. Bremer, Reducing Judicial Stress through Mentoring, 87 JudicAture 244 (2004).

45. Chamberlain, Call for Research, supra note 7.
46. E.g., Chamberlain, Stress Triad, supra note 13; Jaffe, Vicarious Trauma in Judges, supra note 10; Miller, Judges' Reactions, supra note 13.

47. Shuman, Health Effects, supra note 18, at 288.

48. Bornstein, Juror Reactions, supra note 9, at 328.

49. Lenore S. Radloff, The CES-D Scale: A Self-report Depression Scale for Research in the General Population, 1 Applied Psychol. Measurement 385, (1977). 
Anxiety Inventory developed by Chlan and colleagues, ${ }^{50}$ and seven items from a Post-Traumatic Stress Disorder diagnostic tool $^{51}$ utilized by Bornstein and colleagues 52 in their work on jury stress. Demographic questions including gender and nature of the respondents' judicial positions were also included. Finally, judges indicated whether they had experienced any work-related event that caused stress in the past year.

\section{RESULTS}

\section{Dealing with Juror Stress}

The first research question focused on whether judges feel responsible for juror stress. Judges were asked their general level of responsibility and what strategies they have used to reduce jurors' stress. Differences based on gender and experience with a work-related stress/safety incident were investigated to address Research Question 5.

Responsibility for Juror Stress. Judges were asked to indicate if they believed the court has a responsibility to prevent, address, or minimize juror stress on a seven-point scale $(1=$ no responsibility; 7 = full responsibility). Descriptive statistics revealed that judges assume a moderate to high amount of responsibility for juror stress $(M=5.47, M d n=6.0, S D=1.15)$. Independent-sample t-tests revealed no significant differences based on gender or experience with a work-related stress/safety incident (all $p s>.51$ ).

Stress-Reduction Strategies. Judges were also asked to indicate what steps they had taken to reduce juror stress by checking items on a list of 41 potential strategies (compiled by the researchers). Some examples of strategies included "encourage or grant a change of venue" and "shorten length of court days for jurors." Thirty-six judges were not included in this analysis because they indicated that they did not work with juries. The most commonly used strategies were (in order): (1) Explaining the trial process to jurors before the trial; (2) attempting to maintain positive rapport with jurors; (3) instructing court officials to be sensitive to jurors' needs; (4) asking jurors about their wishes about lunchtime, quitting time, etc., (5) explaining jury instructions; and (6) limiting delays. Seven judges also indicated other strategies that they used to prevent juror stress, many of which focused on establishing a good relationship with jurors, instilling confidence in jurors, and reassuring jurors about any uncertainties about the trial. A full summary of the frequency of strategies used by judges to prevent juror stress is provided in Table 1.

An aggregate "strategy use" variable was created to determine if there were any differences in frequency of strategy use

50. Linda Chlan, Kay Savik, \& Craig Weinert, Development of a Shortened State Anxiety Scale from the Spielberger State-Trait Anxiety Inventory (STAI) for Patients Receiving Mechanical Ventilatory Support, 11 J. NuRSING MEASUREMENT 283 (2003) [hereinafter, Chlan, Short STAI].

51. Edna B. Foa, Laurie Cashman, Lisa Jaycox \& Kevin Perry, The Validation of a Self-Report Measure of Posttraumatic Stress Disorder: The Posttraumatic Diagnostic Scale, 9 Psychol. Assessment 445 (1997) [hereinafter, Foa, PTSD Scale].

52. Bornstein, Juror Reactions, supra note 9, at 328.
TABLE 1: NUMBER AND PERCENTAGE OF STRATEGIES USED TO REDUCE JUROR STRESS

\begin{tabular}{|c|c|}
\hline Strategy & $\begin{array}{l}\text { Number \& } \\
\text { Percentage }\end{array}$ \\
\hline Encourage or grant a change of venue & $n=2 ; 1.6 \%$ \\
\hline Encourage or grant a delay in beginning of trial & $n=13 ; 10 \%$ \\
\hline Specifically address possible trial stress during voir dire & $n=44 ; 34 \%$ \\
\hline Permit attorneys to address trial stress during voir dire & $n=37 ; 29 \%$ \\
\hline Explain the trial process to jurors before trial & $n=87 ; 68 \%$ \\
\hline Encourage attorneys to change trial strategy & $n=11 ; 8.6 \%$ \\
\hline Encourage attorneys to alter evidentiary presentation & $n=16 ; 13 \%$ \\
\hline Require attorneys to alter evidentiary presentation & $n=2 ; 1.6 \%$ \\
\hline Refuse to allow certain evidence & $n=21 ; 16 \%$ \\
\hline Instruct witnesses to modify their testimony & $n=0 ; 0 \%$ \\
\hline Instruct witnesses to clarify their testimony & $n=14 ; 11 \%$ \\
\hline Permit jurors to take notes during trial & $n=67 ; 52 \%$ \\
\hline Permit jurors to ask questions during trial & $n=30 ; 23 \%$ \\
\hline Permit jurors to discuss case among themselves during trial & $n=14 ; 11 \%$ \\
\hline Alter typical order of trial & $n=16 ; 13 \%$ \\
\hline Limit delay & $n=73 ; 57 \%$ \\
\hline Shorten length of court days for jurors & $n=43 ; 37 \%$ \\
\hline Provide additional breaks for jurors & $n=71 ; 56 \%$ \\
\hline Ask jurors their wishes about lunchtime, quitting time, etc. & $n=75 ; 59 \%$ \\
\hline Encourage attorneys to make motions when jurors not present & $n=36 ; 28 \%$ \\
\hline Require attorneys to make motions when jurors not present & $n=46 ; 36 \%$ \\
\hline Personally address stress with jurors during trial & $n=12 ; 9 \%$ \\
\hline Discourage side bar conferences & $n=15 ; 12 \%$ \\
\hline Provide special seating for jurors & $n=20 ; 16 \%$ \\
\hline Control public access to court room & $n=12 ; 9 \%$ \\
\hline Empty court room & $n=3 ; 2.3 \%$ \\
\hline Shield jurors from media & $n=30 ; 23 \%$ \\
\hline As judge, attempt to maintain positive rapport with jurors & $n=83 ; 65 \%$ \\
\hline Instruct court officials to be sensitive to juror needs & $n=83 ; 65 \%$ \\
\hline Designate court official to monitor jurors during trial & $n=52 ; 41 \%$ \\
\hline Designate court official to discuss stress with jurors during trial & $n=3 ; 2.3 \%$ \\
\hline Explain jury instructions clearly & $n=73 ; 57 \%$ \\
\hline Provide special amenities in jury room & $n=45 ; 35 \%$ \\
\hline Accept hung jury sooner than usual & $n=3 ; 2.3 \%$ \\
\hline Contact family member to ascertain juror's well-being & $n=6 ; 4.7 \%$ \\
\hline Permit family contacts during sequestration & $n=6 ; 4.7 \%$ \\
\hline Make available posttrial debriefing by a court official & $n=10 ; 7.8 \%$ \\
\hline Make available posttrial debriefing by a judge & $n=48 ; 38 \%$ \\
\hline Make available posttrial debriefing by a mental-health expert & $n=6 ; 4.7 \%$ \\
\hline Refer jurors to available mental-health counseling & $n=7 ; 5.5 \%$ \\
\hline Offer to pay for mental-health counseling & $n=2 ; 1.6 \%$ \\
\hline Others (please specify) & $n=7 ; 5.5 \%$ \\
\hline
\end{tabular}


based on gender or experiencing a work-related stress/safety incident. Although judges utilized an average of nearly 10 different strategies to reduce jurors stress $(M=9.71 ; M d n=12 ; S D$ $=7.13$ ), independent-sample $\mathrm{t}$-tests revealed no significant differences based on these two variables (all $p s>.39$ ).

\section{Judge Stress}

The second research question focused on judges' own experiences with stress. Judges were asked about general and occupational stress, the effects of stress on work performance, specific stressful situations, and physical and emotional manifestations of stress. Respondents also completed clinical scales designed to measure PTSD, depression, and anxiety. In addition, analyses were conducted to determine whether individual differences affected stress levels, as stated in Research Question 5.

General Stress. Judges indicated the amount of stress they had experienced over the past year on a seven-point scale $(1=$ no stress; $7=$ extreme stress). In general, judges indicated that they had experienced a moderate amount of stress $(M=4.29$, $M d n=4.0, S D=1.31$ ). Analysis revealed a gender difference in the reporting of general stress $(t \quad(151)=-3.66 ; p=.00)$. Specifically, women reported experiencing higher levels of stress $(M=4.75 ; S D=1.20)$ than men $(M=3.99 ; S D=1.29)$. Experiencing a work-related stressful incident was also related to general stress $(t(152)=2.76 ; p=.01)$. Not surprisingly, judges who experienced a work-related stress/safety incident were significantly more likely to experience general stress ( $M$ $=4.63 ; S D=1.28)$ than those who did not experience such an event $(M=4.04 ; S D=1.29)$.

Trial Stress. Judges were also asked to indicate the amount of stress they experienced during a typical trial on a sevenpoint scale ( $1=$ no stress; $7=$ extreme stress). Similar to results regarding general stress, judges reported experiencing a moderate amount of stress during a typical trial $(M=3.83, M d n=$ $4.0, S D=1.21$ ).

A marginally significant gender effect was found on reports of trial stress $(t(145)=-1.78, p=.08)$. Consistent with trends in reports of general stress, women $(M=4.06 ; S D=1.2)$ reported higher levels of stress than males $(M=3.09 ; S D=$ 1.21). Experiencing a work-related stress/safety incident was not related to trial-related stress $(p=.23)$.

Symptoms of Stress. Judges were asked to indicate how their stress had manifested itself by checking items on a list. Items included on the list were: "anxiety," "sleep disturbances," "nervousness," "irritability," "other emotional symptoms," and "other." Judges who checked "other" were also asked to specify the emotional form that stress had taken. Of the judges, 99 (61\% of the total sample) reported feeling irritable, 79 judges (48\%) reported anxiety, 72 judges (44\%) reported sleep disturbances, and 24 judges (15\%) reported nervousness. A total of 31 judges (19\%) indicated that they experienced other emotional forms of stress, the most common of which were eating problems, depression, and anger.

Differences in emotional stress based on gender and experiencing a work-related stress/safety incident were examined by

53. Foa, PTSD Scale, supra note 51 combining all reported emotional forms of stress (from the list) into one numerical value ranging from zero to six. Descriptive statistics revealed that judges typically reported more than one emotional manifestation of stress $(M=1.86$; $M d n=2 ; S D=1.21$ ). Independent-sample t-tests revealed no significant difference in reported emotional stress between males and females $(\mathrm{p}=.52)$. Judges who had experienced a stress/safety incident $(M=2.17 ; S D=1.14)$ were more likely to report emotional manifestations of stress than judges who had $\operatorname{not}(M=1.71 ; S D=1.2 ; t(159)=2.44, p=.02)$.

Similar to emotional symptoms of stress, judges were asked to indicate which physical forms of stress they had experienced. The list compiled by the authors included "headaches," "muscle tension," and "other." Judges who checked "other" were also asked to specify the physical form that stress had taken. Of the judges, 89 ( $55 \%$ of all judges in the sample) indicated that they had experienced muscle tension, 43 judges (26\%) indicated that they had experienced headaches, and 55 judges (34\%) indicated they had experienced some other form of physical stress. Of the judges who indicated that they suffered other physical forms of stress, 13 reported feeling exhausted or fatigued, 9 reported eating problems, 7 reported stomach problems, and 5 reported back, chest, or muscle pain. Other reported physical manifestations of stress included shingles, hypertension, rashes, and diabetes.

Differences in physical manifestations of stress based on gender and experience with a work-related stress/safety incident were examined by combining all reported physical forms of stress (from the list) into one numerical value ranging from 0 to 3. Descriptive statistics revealed that judges typically experience one physical manifestation of stress $(M=1.14 ; M d n=1$; $S D=.83$ ). Independent-sample t-tests revealed no significant differences based on gender or on experiencing a work-related stress/safety incident (all ps > 1.29).

Judges' Daily Experiences. Respondents were given seven statements from Foa, Cashman, Jaycox, and Perry's PostTraumatic Stress Disorder diagnostic scale ${ }^{53}$ to rate on a fivepoint scale $(1=$ not at all; $5=$ extremely $)$ indicating how descriptive each symptom was of their daily experiences as a judge. On average, "feeling distant or cut off" and "feeling irritable or angry" were most descriptive of judges' daily experiences (see Table 2 for a full summary).

TABLE 2: JUDGES EXPERIENCES WITH STRESS SYPMTOMS

\begin{tabular}{|l|l|}
\hline \multicolumn{1}{|c|}{ Statement } & \multicolumn{1}{|c|}{ M, Mdn, SD } \\
\hline Having upsetting thoughts or images about the trial & $1.56 ; 1.00 ; .79$ \\
\hline Feeling distant or cut off from people around you & $2.29 ; 2.00 ; 1.09$ \\
\hline Feeling emotionally numb & $1.64 ; 1.00 ; .90$ \\
\hline Feeling irritable or having fits or anger & $2.15 ; 2.00 ; .95$ \\
\hline Having trouble concentrating & $1.87 ; 2.00 ; .87$ \\
\hline Being overly alert & $1.68 ; 1.00 ; .97$ \\
\hline Being jumpy or easily startled & $1.57 ; 1.00 ; .93$ \\
\hline Note: $(1=$ not at all; $5=$ extremely) & \\
\hline
\end{tabular}


Numerical responses were combined from each of the seven statements to create a measure of PTSD-type symptoms with scores ranging from 7 to 35 . On average, judges exhibited moderately low scores on this measure of stress $(M=12.74$; $M d n=12 ; S D=4.56$ ). Differences in stress scores based on gender and experience were examined through independentsample t-tests. Consistent with the self reported measure of general stress, females were more likely to experience these symptoms of stress $(M=13.79 ; S D=5.05)$ than males $(M=$ 11.97; $S D=3.96 ; t(136)=-2.36, p=.02)$. Analysis also revealed that judges who had experienced a work related stress/safety incident $(M=13.98 ; S D=5.17)$ were more likely to report higher levels of stress than judges who had not $(M=$ $11.81 ; S D=3.88 ; t(100)=2.70 ; p=.01)$.

Depression and anxiety. Respondents also completed two clinical measures which assessed depression and anxiety. The first was the Center for Epidemiology Studies Depression Scale (CESDS), a 20-item self-report scale intended to measure depressive symptoms in community populations. ${ }^{44}$ Items emphasize affect (e.g., feelings of depressed mood, guilt, hopelessness) and psychomotor impairment (e.g., loss of appetite, sleep disturbances) and require respondents to report how often they experienced each symptom in the previous week on a four-point scale $(0=$ rarely or none of the time; $3=$ most or all of the time). Scores range from 0 to 60 , and the average of the general population is approximately 8.7.55 Twenty percent of the general population falls above a score 16 , which has often been used as a cutoff suggesting depressive impairment. ${ }^{56}$

Overall, judges' average score on the CESDS was 15.52 (SD $=5.72, M d n=14)$. This number exceeds the mean score in the general population and also falls close to one generally utilized cutoff score of 16. Significant gender differences were found with respect to scores on the CESDS. Females' scores exceeded the impairment cutoff score of 16 and were significantly higher $(M=17.69 ; S D=6.28)$ than those of male respondents $(M=$ $14.01 ; S D=4.62 ; t(121)=3.71 ; p<.001$ ), whose scores fell below the cutoff. Additionally, those judges who had previously experienced a work related stress/safety incident also scored above the impairment cutoff of $16(M=17.41 ; S D=$ 6.05), scoring significantly higher than those lacking such an experience $(M=14.26 ; S D=5.15 ; t(122)=3.12 ; p<.003)$.

Participants also completed a shortened 6-item form of the Spielberger State Anxiety Inventory ${ }^{57}$ developed by Chlan and colleagues. ${ }^{8}$ Spielberger's STAI has been widely utilized as a measure of both enduring (trait) and changing (state).59 The brief form employed in the current study targets trait anxiety and has been demonstrated to be highly correlated (0.92) with the full 20-item version, with a Cronbach's alpha of 0.78.60 Participants responded on 4-point scales in the 6-item version, with possible cumulative scores ranging from 4 to 24 . The average score of judges was $18.56(S D=4.20, M d n=19)$, falling in the moderately high end of the range of possible scores. Analyses did not reveal a significant gender difference on participant scores on the shortened STAI $(p>.22)$. There was, however, a significant difference with regards to previous experience with a work related stress/safety incident. Judges who had experienced such an incident scored significantly higher on the brief STAI $(M=12.55 ; S D=4.23)$ than those who had not $(M=10.71 ; S D=4.04 ; t(132)=2.54 ; p<.02)$.

Effects of Stress. Judges were asked to indicate the degree to which their ability to fulfill responsibilities had been compromised by high levels of stress on a seven-point scale $(1=$ not compromised; 7 = very compromised). In general, judges indicated that their ability to fulfill responsibilities had been only slightly compromised by stress $(M=2.23 ; M d n=2.0 ; S D=$ 1.52). However, a total of 27 judges ( $17 \%$ of the total sample) indicated that their responsibilities had been at least moderately compromised (rating of 4 or higher) due to high levels of stress.

Independent-sample t-tests were used to determine if there were any differences in the reporting of compromised responsibilities based on gender and/or experience with a work related stress/safety incident. Females $(M=2.80 ; S D=1.18)$ reported that their responsibilities had been significantly more compromised by stress than males $(M=2.80 ; S D=1.18 ; t(81)$ $=-3.37, p<.01)$. However, experiencing a work related stressful incident had no statistically significant effect on the reporting of compromised responsibilities $(p=.11)$.

Judges were also asked an open ended question about how their functions were specifically compromised. Judges commonly reported a decrease in productivity resulting from stress and heavy workloads $(n=26)$. Many of these judges reported a decrease in efficiency stemming from procrastination, avoidance of workplace duties, loss of energy, and fatigue. Twentyone judges also reported that stress had compromised their ability to maintain appropriate courtroom demeanor. Specifically, judges indicated that they had become irritable, angry, and impatient with courtroom actors, especially lawyers. Thirteen judges indicated stress had compromised their ability to concentrate in the workplace, suggesting that case outcomes may have been compromised because judges were distracted or unable to focus. A total of eight judges explicitly stated that stress had compromised decisions that had been made. One judge explained that stress had led to "sloppy decision making," and several other judges indicated
54. Lenore S. Radloff, The CES-D Scale: A Self-report Depression Scale for Research in the General Population, 1 Applied Psychol. MeAsurement 385 (1977).

55. Myrna M. Weissman, Diane E. Sholomskas, Margaret Pottenger, Brigitte A. Prusoff, \& Ben Z. Locke, Assessing Depressive Symptoms in Five Psychiatric Populations: A Validation Study. 106 Ам. J. EPidemiology 203 (1977).

56. Lenore S. Radloff \& Ben Z. Locke, The Community Mental Health Assessment Survey and the CESD Scale, in COMmunity SuRvers OF Psychiatric DisORders 177 (Myrna Weisman ed., 1986).
(However, cutoff scores of 23 or greater have also been utilized, see Ian McDowell \& Claire Newell, Measuring Health: A Guide to Rating Scales and Questionnaires 87 (1996).)

57. Charles D. Spielberger, Manual for the State-Trait AnXiety INVENTORY (STAI) 1 (1983).

58. Chlan, Short STAI, supra note 50.

59. Id, at 285 .

60. Id, at 290 . 
that they were not able to remain impartial when deciding cases.

Stressful Situations. Judges were asked to rate the level of stress they experienced stemming from several scenarios on a five-point scale ( $1=$ not at all; $5=$ extremely). The highest levels of reported stress stemmed from crimes against children $(M$ $=3.0)$, sexual crimes $(M=2.85)$, and violent crimes $(M=$ 2.74). Sixty-six percent of judges reported that crimes against children were at least moderately stressful, $61 \%$ of judges reported that sexual crimes were at least moderately stressful, and $57 \%$ of judges reported that violent crimes were are least moderately stressful.

Judges reported that media coverage during a trial was somewhat stressful $(M=2.15)$, and $37 \%$ believed that is was at least moderately stressful. Judges also reported that they were a little stressed (on average) over public identification ( $M=$ $2.0)$ and, more generally, safety concerns $(M=2.2)$. Twentythree percent of judges reported that they were at least moderately stressed about being publicly identified, while 33\% percent of judges experienced stress stemming from safety concerns. Characteristics of the parties, victims, and court officials were all somewhat stressful for judges on average $(M=2.07$, 2.05 , and 2.15, respectively). Thirty-three percent of judges reported at least moderate amounts of stress from characteristics of the parties, $29 \%$ of judges were at least moderately stressed from characteristics of the victims, and 33\% of judges were at least moderately stressed from characteristics of court officials.

Factors specifically related to trial were also significant sources of stress for judges. Long trials, boring trials, and trial interruptions were all reported (on average) to be at least somewhat stressful ( $M=2.38,2.40$, and 2.71 , respectively). Fortyfour percent of judges reported at least marginal stress from long trials, and many judges reported at least moderate stress stemming from boring trials (41\%), and trial interruptions (53\%). A summary of the means and percentages of stressful situations experienced by judges is provided in Table 3.

Numerical responses were combined from each of the 41 situations provided by the researchers in the instrument to create another measure of stress with scores ranging from 41 to 205. On average, judges scored 77.85 on this stress scale (Mdn $=75 ; S D=19.53$ ), indicating only a mild to moderate stress as a result of these situations. Analysis revealed a marginal effect for gender in the expected direction $(t(59)=-1.76, p=.08)$. Consistent with the other measures of stress in the survey, females were (marginally) more likely to experience stress ( $M$ $=85.93 ; S D=20.08)$ than males $(M=75.46 ; S D=19.32)$ as a result of these situations. There was no statistically significant effect found for experience with a work-related stress/safety situation on this measure $(p=.17)$.

Judges were asked to report additional stressful situations that were not on the list of potential stressful situations. Heavy workload $(n=20)$ was the most commonly mentioned source of stress among judges. Similarly, judges reported that lack of time, resources, and staff led to stress $(n=15)$. Other sources of stress included the attitudes and behavior of parties $(\mathrm{n}=$ $19)$, the nature of the political process $(n=9)$, tension among colleagues and staff $(n=4)$, pressures related to campaigning for election $(n=3)$, and balancing family and work $(n=3)$.
TABLE 3: STRESSFUL SITUATIONS EXPERIENCED BY JUDGES

\begin{tabular}{|c|c|}
\hline Situation & $\begin{array}{c}\text { Mean; } \\
\text { Percentage }\end{array}$ \\
\hline Jury selection (i.e., voir dire) & $1.72 ; 18 \%$ \\
\hline Pre-existing medical or psychological problems & $1.43 ; 9 \%$ \\
\hline Troubles at home & $1.96 ; 24 \%$ \\
\hline Media coverage of the trial & $2.15 ; 37 \%$ \\
\hline Cameras in the courtroom & $1.78 ; 10 \%$ \\
\hline Being publicly identified as a judge & $1.96 ; 23 \%$ \\
\hline Fear of reprisal/concerns for personal safety & $2.20 ; 33 \%$ \\
\hline Characteristics of the criminal defendant & $1.74 ; 17 \%$ \\
\hline Characteristics of the parties & $2.07 ; 34 \%$ \\
\hline Characteristics of the victims & $2.05 ; 30 \%$ \\
\hline Interactions with court officials (e.g., rude behavior) & $2.15 ; 34 \%$ \\
\hline Crimes against children & $3.00 ; 67 \%$ \\
\hline Sexual crimes & $2.85 ; 61 \%$ \\
\hline Violent crimes & $2.74 ; 58 \%$ \\
\hline Issues/Evidence with a personal impact/meaning & $2.19 ; 41 \%$ \\
\hline Disturbing/Grisly evidence & $2.33 ; 37 \%$ \\
\hline Complex or technical evidence & $2.17 ; 31 \%$ \\
\hline Expert testimony & $1.79 ; 17 \%$ \\
\hline Long trials & $2.38 ; 44 \%$ \\
\hline Boring trials & $2.40 ; 41 \%$ \\
\hline Trial interruptions/delays & $2.71 ; 54 \%$ \\
\hline Side bars/Discussions outside hearing of jurors & $1.63 ; 15 \%$ \\
\hline Attorneys' behavior during trial & $2.74 ; 56 \%$ \\
\hline Objections/Arguments by attorneys & $1.96 ; 24 \%$ \\
\hline The adversarial system & $1.71 ; 17 \%$ \\
\hline Instructions to disregard evidence/testimony & $1.38 ; 5 \%$ \\
\hline Explaining jury instructions & $1.33 ; 8 \%$ \\
\hline Deciding which jury instructions to give & $1.76 ; 19 \%$ \\
\hline Jury deliberations (e.g. waiting, fear of arguments) & $1.26 ; 1 \%$ \\
\hline Fear of making a mistake in giving instructions & $1.64 ; 13 \%$ \\
\hline Fear of making a mistake in deciding motions & $2.04 ; 24 \%$ \\
\hline Dissension/Differences among jurors & $1.31 ; 3 \%$ \\
\hline Hung jury & $1.46 ; 12 \%$ \\
\hline Sentencing a criminal defendant & $2.08 ; 32 \%$ \\
\hline Determinations regarding jurors' decisions about death penalty & $1.60 ; 20 \%$ \\
\hline Concerns about community reactions to verdict & $1.82 ; 18 \%$ \\
\hline Photographs or videos presented as evidence & $1.77 ; 21 \%$ \\
\hline Verbal testimony presented as evidence & $1.52 ; 10 \%$ \\
\hline Your feelings for the victim (or plaintiff) and the victim's family & $1.92 ; 21 \%$ \\
\hline Your feelings for the defendant and the defendant's family & $1.82 ; 15 \%$ \\
\hline Fear of making a mistake and reaching the wrong verdict & $2.28 ; 33 \%$ \\
\hline \multicolumn{2}{|c|}{$\begin{array}{l}\text { Note: "Mean percentage" indicates the percentage of judges who indicated } \\
\text { that they experienced at least moderate amounts of stress from the situation } \\
(1=\text { Not at all; } 5=\text { extremely }) \text {. }\end{array}$} \\
\hline
\end{tabular}


Suggestions for reducing the stress of judges. Respondents were also asked an open-ended question requesting that they provide coping strategies that judges could use to reduce stress (see Table 4).

\section{TABLE 4: SUGGESTIONS FOR REDUCING STRESS}

\begin{tabular}{|l|c|c|}
\hline \multicolumn{1}{|c|}{ Strategy } & $\#$ & \% (of total) \\
\hline Exercise & 15 & 13.19 \\
\hline Time off/sabbatical & 12 & 12.09 \\
\hline Interaction with professional colleagues & 11 & 10.99 \\
\hline Social interaction (outside of work) & 10 & 10.99 \\
\hline Increase courthouse security & 10 & 10.99 \\
\hline Stress-management training & 10 & 7.69 \\
\hline Balance in life & 7 & 6.59 \\
\hline Reduce workloads & 6 & 4.40 \\
\hline Prayer/Religion & 4 & 2.20 \\
\hline Greater psychological awareness & 2 & 2.20 \\
\hline Time management & 2 & 2.20 \\
\hline More resources (staff, technology) & 2 & 2.20 \\
\hline TOTAL & 91 & 100 \\
\hline
\end{tabular}

Of the 91 total suggestions, exercise and time off/sabbaticals were the most commonly suggested means of addressing judicial stress $(n=15)$. Interaction with professional colleagues (e.g., through mentoring, support groups, and collaboration) and involvement with nonoccupational social networks (e.g., family, friends) were both also among the more commonly suggested strategies ( $\mathrm{n}=12$ and 11 , respectively). Increased court house security (10) and stress-management training (10) were also advocated by respondents.

\section{Safety Concerns}

To address Research Question 3, concerning judges' perceptions of safety and what measures they take to protect themselves, respondents were asked a variety of questions regarding safety issues. These items related to perceptions of safety, sources of safety concern, and experiences with safety-related incidents. Individual differences, including gender and experience with a work-related stress/safety incident, were also assessed to address Research Question 5.

Personal Safety. Judges specified their level of concern for their personal safety on a seven-point Likert-type scale $(1=$ no concerns; $7=$ extremely concerned). Overall, judges exhibited moderate amounts of concern for personal safety $(M=2.80 ; S D$ $=1.41 ; M d n=2.00)$. Further analyses revealed significant gender differences with regards to personal-safety concerns, with females $(M=3.20 ; S D=1.19)$ reporting greater levels of concern than their male counterparts $(M=2.51 ; S D=1.53 ; t(141)$ $=3.00, p<.01$ ). Additionally, those judges who had previously experienced a work-related stress/safety incident also expressed greater concern for personal safety $(M=3.15 ; S D=$ 1.56) than those lacking such an experience $(M=2.55 ; S D=$ $1.24 ; t(142)=2.51 ; p<.02)$.
Safety of One's Family. Respondents also specified their individual levels of concern with respect to the safety of their family on a similar seven-point scale. Taken together, judges expressed moderate amounts of concern for family safety $(M=$ 3.11; $S D=1.61 ; M d n=3.00$ ). A two-tailed paired-sample t-test revealed that concern for family was significantly greater that concern for personal safety $(t(144)=3.94, p<.001)$. Analyses revealed no significant gender differences ( $>$ > .10); however, judges who had previously experienced a work-related stress/safety incident, exhibited greater concern for family safety $(M=3.48 ; S D=1.80)$ than judges who had not $(M=$ $2.85 ; S D=1.40 ; t(141)=2.32 ; p<.03)$.

Specific Safety Concerns. Judges were also asked to rate their concern for 19 different work-related safety threats on five-point scales $(1=$ not at all to $5=$ extremely). Results are displayed in Table 5.

\begin{tabular}{|c|c|}
\hline \multicolumn{2}{|c|}{$\begin{array}{l}\text { TABLE 5: RATINGS OF CONCERN } \\
\text { FOR SPECIFIC SAFETY-RELATED THREATS }\end{array}$} \\
\hline Specific Threat & M, Mdn, SD \\
\hline Inappropriate letters & $1.74 ; 2.00 ; .68$ \\
\hline Inappropriate phone calls & $1.83 ; 2.00 ; .68$ \\
\hline Inappropriate faxes & $1.59 ; 1.00 ; .75$ \\
\hline Threatening letters & $2.13 ; 2.00 ; .99$ \\
\hline Threatening phone calls & $2.10 ; 2.00 ; 1.03$ \\
\hline Threatening faxes & $1.90 ; 2.00 ; 1.03$ \\
\hline Receiving a bomb or anthrax in the mail & $1.52 ; 1.00 ; .89$ \\
\hline Being inappropriately approached & $2.46 ; 2.00 ; .97$ \\
\hline Being followed & $2.06 ; 2.00 ; 1.05$ \\
\hline Being confronted face-to-face & $2.26 ; 2.00 ; .99$ \\
\hline Being physically assaulted & $2.06 ; 2.00 ; .95$ \\
\hline Being seriously injured by a defendant & $1.85 ; 2.00 ; .95$ \\
\hline Being seriously injured by a defendant's family & $1.82 ; 2.00 ; .93$ \\
\hline Being seriously injured by court personnel & $1.13 ; 1.00 ; .18$ \\
\hline Being seriously injured by random person in the courtroom & $1.60 ; 1.00 ; .74$ \\
\hline Having a gun pulled on you & $1.88 ; 2.00 ; .95$ \\
\hline Having a knife pulled on you & $1.82 ; 2.00 ; .90$ \\
\hline Bomb threats in the courthouse & $1.74 ; 2.00 ; .98$ \\
\hline Anthrax in the courthouse & $1.35 ; 1.00 ; .71$ \\
\hline
\end{tabular}

The specific threats judges were most concerned about were being inappropriately approached $(M=2.46 ; S D=.99)$, being confronted face-to-face $(M=2.26 ; S D=.99)$, receiving threatening letters $(M=2.13 ; S D=.99)$ or phone calls $(M=2.10 ; S D$ $=1.03)$, being followed $(M=2.06 ; S D=1.05)$, and being physically assaulted $(M=2.06 ; S D=.99)$. Alternatively, respondents were least concerned about being seriously injured by court personnel $(M=1.13 ; S D=.18)$ and anthrax in the courthouse $(M=1.35 ; S D=.71)$. 
Only one gender difference emerged in these analyses. Female respondents ( $M=2.35 ; S D=1.07)$ were significantly more concerned about being followed than males $(M=1.83$; $S D=.91 ; t(141)=3.07 ; p<.01)$. Additionally, those judges who had previous experience with a safety/stress incident at work rated being significantly more concerned with receiving inappropriate letters $(M=1.92 ; S D=.91)$ than their counterparts who had never experienced such an event $(M=1.65 ; S D$ $=.59 ; t(141)=2.32 ; p<.04)$.

Experiences with Safety Incidents. Judges reporting that they had previously experienced a threatening event were asked to specify what types of threats they had encountered. A total of 26 different types of events were reported (see Table 6).

Inappropriate or threatening letters were the most common $(55,33.5 \%)$, followed by inappropriate or threatening phone calls $(27,16.5 \%)$, and death or bomb threats $(13,7.9 \%$, each).

\begin{tabular}{|l|c|c|}
\multicolumn{3}{|c|}{ TABLE 6: EXPERIENCES WITH } \\
\multicolumn{1}{|c|}{ Incident } & $\#$ & $\%$ (of total) \\
\hline Inappropriate/Threatening letters & 55 & 25.82 \\
\hline Inappropriate/Threatening calls & 27 & 12.68 \\
\hline Death threats & 19 & 8.92 \\
\hline Bomb threats & 13 & 6.10 \\
\hline $\begin{array}{l}\text { Face-to-face confrontation (with litigant or } \\
\text { family member) }\end{array}$ & 13 & 6.10 \\
\hline Verbal threats in court & & \\
\hline Inappropriately approached & 12 & 5.63 \\
\hline Threats to home or family & 11 & 5.16 \\
\hline Physically attacked in court & 10 & 4.69 \\
\hline False accusations & 10 & 4.69 \\
\hline Other incident & 10 & 4.69 \\
\hline Weapons seized at courthouse/in courtroom & 7 & 3.29 \\
\hline Had a gun pointed at & 4 & 2.82 \\
\hline Target of pranks & 1.88 \\
\hline Anthrax threats & 4 & 1.88 \\
\hline Threats against staff members & 1 & 0.94 \\
\hline Physically assaulted outside of courthouse & 1 & 0.47 \\
\hline Fellow judge shot & 1 & 0.47 \\
\hline Personal residence attacked (arson) & 1 & 0.47 \\
\hline Threat requiring personal police escort & 1 & 0.47 \\
\hline Escape attempt by defendant in court & 1 & 0.47 \\
\hline Followed outside of courthouse & 1 & 0.47 \\
\hline Public postings discouraging reelection & 1 & 0.47 \\
\hline Tires slashed & 1 & 0.47 \\
\hline Witness attacked in court & 1 \\
\hline TOTAL & 1 & \\
\hline
\end{tabular}

Face-to-face confrontations involving either a litigant or a relative of a litigant $(12,7.3 \%)$, verbal threats in court $(9,5.5 \%)$, and being inappropriately approached $(8,4.9 \%)$ were also among the more frequently reported incidents reported by respondents.

Precautionary Measures. Judges were asked what measures they had taken to address their safety concerns by checking items from a checklist of 14 possible measures. Seventy percent of judges indicated they had taken at least one precautionary measure and nearly one-third (31.9\%) specified taking over three. Respondents listed a total of 336 precautionary measures (see Table 7).

\section{TABLE 7: PRECAUTIONARY MEASURES TAKEN TO} ADDRESS SAFETY CONCERNS

\begin{tabular}{|l|c|c|}
\hline \multicolumn{1}{|c|}{ Safety Precaution } & $\#$ & \% (of total) \\
\hline Purchased a cellphone & 65 & 18.84 \\
\hline Added more security in the courtroom & 54 & 15.65 \\
\hline $\begin{array}{l}\text { Increased home security (e.g., alarms, motion } \\
\text { sensitive lighting, etc.) }\end{array}$ & 49 & 13.24 \\
\hline Purchased cellphones for family & 46 & 13.33 \\
\hline Purchased a firearm & 36 & 10.43 \\
\hline Varied schedule & 28 & 8.12 \\
\hline Bought mace/pepper spray & 11 & 3.19 \\
\hline Stopped working late hours & 10 & 2.90 \\
\hline Changed locks at personal residence & 10 & 2.90 \\
\hline Purchased a guard dog & 10 & 2.90 \\
\hline Enrolled in self-defense classes & 7 & 2.03 \\
\hline $\begin{array}{l}\text { Take additional measures to protect family } \\
\text { (e.g., create emergency plans) }\end{array}$ & 6 & 1.73 \\
\hline Enlisted security detail/police escort & 4 & 1.16 \\
\hline $\begin{array}{l}\text { Increased general awareness of personal } \\
\text { surroundings }\end{array}$ & 4 & 1.16 \\
\hline Changed travel route & 2 & 0.57 \\
\hline Wore bulletproof vest & 1 & 0.28 \\
\hline Changed personal phone number & 1 & 0.28 \\
\hline Other & 236 & 100 \\
\hline TOTaL & & \\
\hline
\end{tabular}

The most frequently reported response was the purchase of a cellphone $(65,17.6 \%$ of total), followed by adding to existing courtroom security $(54,14.6 \%)$, increasing security at personal residence $(49,13.2 \%)$, buying cellphones for family members $(46,12.4 \%)$, and purchasing a firearm (36, 9.7\%). The number of precautionary measures taken (e.g., installing safety alarms in home, buying a gun) was positively associated with stress experienced during a trial $(r=.18, p<.05)$, concerns about personal safety $(r=.38, \mathrm{p}<.01)$, and safety of family $(r=.36, p<.01)$. Overall, judges adopted an average of 2.07 
safety precautions $(S D=1.91, M d n=2.00)$. There were no significant differences between individuals who had experienced a work-related stress/safety incident and those who had not, or between male and female judges (all ps > .4)

\section{Relationship between Stress and Safety}

Research Question 4 focused on the potential relationship between judges' perceptions of safety and their experiences of stress. Analyses revealed significant positive associations between ratings of general experiences of stress and concerns about one's own personal safety $(r=0.36, p<.01)$ and safety of family $(r=0.29, p<.01)$. A similar positive relationship was found between stress experienced during a trial and concerns about personal $(r=.24, p<.01)$ and family $(r=.27, p<.01)$ safety. The number of physical and emotional symptoms of stress was positively correlated with both concern of personal $(r=0.22, p<.05)$ and family $(r=0.27 . p<.01)$ safety. Scores on the CESD were also positively associated with personal- and family-safety concerns $(r=0.371, p<.001 ; r=.302 ; p<.001$, respectively). Conversely, scores on the STAI short form were negatively correlated with safety concerns (personal: $r=$ 0.357, $p<.001$; family: $r=-0.312, p<.001)$.

Concern for personal safety was positively correlated with ratings on each of the PTSD symptom measures. These items, on which respondents reported the extent to which a variety of negative psychological experiences were judged to be "descriptive of daily experience as a judge," included: having upsetting thoughts/images $(r=0.20, p<.05)$, feeling distant or cut off $(r$ $=0.26, p<.01)$, feeling emotionally numb $(r=0.21, p<.01)$, feeling irritable $(r=0.27, p<.01)$, experiencing difficulties concentrating $(r=0.23, p<.01)$, being overly alert $(r=0.60, p$ $<.01)$, and being jumpy or easily startled $(r=0.54, p<.01)$.

Likewise, concerns about the safety of one's family were also positively correlated to a variety of these experiences, including: feeling distant or cut off $(r=0.23, p<.01)$, feeling irritable $(r=0.20, p<.05)$, having difficulties concentrating $(r=$ $0.23, p<.01)$, being overly alert $(r=0.60, p<.01)$, and being jumpy or easily startled $(r=0.54, p<.01)$.

\section{DISCUSSION}

The overarching purpose of the current exploratory study was to add to the relative paucity of research related to the judicial perspective on stress and safety by addressing five major research questions. Research Question 1 concerned judges' perceptions of jury stress and what measures they have taken to protect jurors. Analyses revealed judges believe that it is their responsibility to protect jurors from stress, and they often take steps to reduce stress among jurors. Judges' beliefs about the court's responsibility to address juror stress, as well as the frequency of strategies used for reducing such stress, were unaffected by either gender or experience with a workrelated stress/safety event. In general, judges used a variety of different strategies to reduce juror stress. The most commonly employed measures paralleled previous research by the NCSC 61 suggesting the protection of jurors from potential stress is accepted among judges as a requisite occupational duty. Regardless of gender or experience with a work-related stress/safety incident, the belief that jurors should be protected, and the propensity to protect jurors, is strong among members of the judiciary surveyed.

Research Question 2 shifted the focus to the stress experienced by judges, what aspects of their occupational duties were most stressful, and how they sought to cope with stress. Results provide support for the notion that members of the judiciary are susceptible to occupational stress. Moreover, the study allowed for the more detailed examination of the nature of stress experienced by judges by integrating numerous dependant measures not utilized in previous research. Three separate measures of stress provide a relatively stable pattern of reporting in which judges reported experiencing moderate levels of stress, both in general and during the course of a given trial. Judges also reported several emotional and physical manifestations of stress, the most prevalent of which were irritability, anxiety, sleep disturbances, muscle tension, and anger. Importantly, several judges believed that occupational stress resulted in more serious emotional and physical maladies, such as eating problems, depression, hypertension, and diabetes. Scores on the CESDS also indicated potential depressive impairment in the responding judges as their scores were almost double that of the average of the general population. Stress did not, however, appear to greatly impact judges' selfreports of their abilities to perform their occupational duties.

The current study also revealed the specific sources of stress for judges. The highest levels of stress for judges stemmed from experiencing cases involving crimes against children, sexual crimes, and violent crimes. Fear over public identification, characteristics of the parties, and safety concerns were all moderately stressful. Judges also reported stress stemming from long and boring trials, trial interruptions, heavy workload, the nature of the political process, and tension among colleagues and staff.

In light of the increasing frequency of accounts of violence at the courthouse and against members of the judiciary, Research Question 3 addressed how judges felt about their personal safety and what protective measures they had adopted in response to safety concerns. Although nearly three in five respondents (58.9\%) indicated previous experience with a work-related threatening situation/event (see Table 6), in general, judges did not report being excessively concerned with safety. They did express greater fear for family safety than personal safety $(M=3.11$ and $M=2.80$ respectively, rated on seven-point scales), though these ratings suggested only modest levels of concern. In addition, judges did not report being deeply concerned with any of the 19 specific threats listed in the survey. Even the individual threats with the highest ratings did not average above 2.5 (the scale midpoint).

The most frequent safety-related incidents experienced by respondents were threatening letters and phone calls, ${ }^{62}$ though more serious threats-such as death threats and face-to-face confrontations-were also among the more frequently 
reported incidents. The most common precautionary measures taken in response to safety concerns were the purchase of a cellphone, increasing security (both at the courthouse and at one's personal residence), and the purchase of a firearm. Over half $(54.6 \%)$ of all respondents reported adopting multiple precautionary measures in response to safety issues.

Our fourth research question bridged two of the aforementioned points of interest by exploring the relationship between judges' perceptions of safety and their experiences of stress. Analyses revealed a generally consistent relationship between safety concerns and measures of stress. Concern for personal and family safety were, for example, positively associated with general stress and stress experienced during the course of a trial, deleterious physical and emotional symptoms, and numerous negative psychological experiences (e.g., irritability, difficulty concentrating) characterized as being descriptive of daily experience as a judge.

The fifth and final research question focused on individual differences in judges' experiences of stress and perceptions of safety in relation to gender and experience of a stress/safetyrelated work incident. In many respects, female judges reported experiencing greater stress and being more concerned with safety issues than their male counterparts. For example, based on several measures of stress, females were consistently more likely to report experiencing general and trial-related stress. In addition, female judges were more likely to report that their responsibilities had been compromised by stress than were male judges. This trend parallels findings from previous judicial stress research, such as that of Jaffe and colleagues, ${ }^{63}$ which found that females exhibited more symptoms of vicarious trauma than males. Females also reported greater levels of concern for personal safety, a finding of considerable interest.

In addition, judges who had previously experienced a workrelated stress/safety incident, such as a threatening or violent act, also consistently reported greater stress and concerns for personal safety on virtually all measures. There were no differences, however, among judges of different types (e.g., criminal vs. civil judges) on any variable. This indicates that all judges in this exploratory study, without regard to their specific duties (e.g., criminal or civil court) experience stress and safety needs similarly.

Several caveats warrant consideration in the current study. The first relates to socially desirable responding. Various design features of the study attempted to encourage unbiased and accurate responses. For example, the amount of personal information asked of the judges was intentionally limited to reduce the possibility that there would be a concern that answers could later be connected to the individual. Moreover, internet surveys have been suggested to have some advantages in eliciting more honest responses in comparison to other methods, such as face-to-face interviews. ${ }^{64}$

Nevertheless, it is possible that the respondents' answers were susceptible to social desirability. For example, the selfreport measure of compromised responsibilities resulting from experiences of stress may have been flawed in that judges were likely to under-report the negative impact of stress on their responsibilities. This is plausible given that: (1) judges may not fully recognize the negative impact of stress; and (2) reporting such vulnerability is not socially desirable because such an admission would have negative implications for their personal legal decisions as well as for the integrity of the legal system. This idea seems to gain credibility when considering judges' specific explanations about how their responsibilities had been compromised. A number of judges reported that stress led to decreased productivity, inappropriate courtroom demeanor, decreased concentration, and compromised courtroom decisions. These explanations do not seem to correspond with the overall low scores seen in the close-ended self-report measures. Thus, when asked directly about the negative effects of stress, judges were apprehensive to report, but when given the opportunity to explain in open-ended fashion, it did appear that judges' were able to list specific ways in which their responsibilities were seriously compromised by stress.

In addition, it is also possible that socially desirable responding may have factored into ratings of safety concerns. That is, respondents may have been less inclined to acknowledge concern about certain threats and safety issues, for example, because such a concession may be perceived as communicating the effectiveness of threats they encounter, which could encourage future acts. While responses did not indicate high levels of fear, a substantial proportion of judges (70.56\%) reported having adopting at least one precautionary measure to address perceived safety issues, suggesting concern was sufficient to motivate reactions among those surveyed.

It should also be noted that the respondents to the survey represented a convenience sample, recruited by their affiliation with either the NCJFCJ, or the University's Judicial Studies program. This sample may not necessarily be representative of the general population of judges and their experiences of stress or perceptions of safety. Future research should build upon the current work by employing a systematic, nationwide sampling plan.

\section{CONCLUSIONS AND RECOMMENDATIONS}

The judicial system in our society is grounded on an assumption that both judges and jurors can function effectively under sometimes severely trying circumstances. Recent research on juror stress has revealed that there are significant impediments to juror functioning under some circumstances. The limited research on judicial stress, including that reported herein, suggests that problems of stress effects are shared by judges as well.

There are a number of conclusions and recommendations that flow from this exploratory study, not the least of which is that much more research is needed in this area, which has received little attention from researchers dealing with occupational stress or those focusing on the functioning of judges within the judicial system. Future research can be guided somewhat by our tentative findings derived from the five research questions we addressed. 
Concerning judges' feelings of responsibility toward jurors, judges commonly take small steps, such as being sensitive to juror needs and explaining trial procedures. However, more formal procedures (e.g., debriefings) may also be needed.65 Such interventions could not only help jurors directly, but might also help judges, who will experience less stress because they are able to better fulfill their occupational duty of protecting jurors.

The issue of stress felt by judges was also examined, revealing a number of stressors and effects, although most judges claimed that these did not affect their functioning as judges. Nevertheless, high amounts of depression or anxiety can affect personal and work life, suggesting that interventions may be needed. A workplace-wide attitude change should take place in courthouses, making therapeutic measures, such as time off or professional help, acceptable for judges. ${ }^{66}$

While interventions have been employed to address juror stress, judges have largely been ignored, though they may benefit from similar measures. For example, posttrial debriefings following difficult trials may also be necessary for judges. In addition, court administrators should be aware of other occupational stressors, such as heavy workload and tension among colleagues, in order to develop policies to relieve any ill effects. These are likely very specific to each court (e.g., each court has specific problems), but the finding that so many judges reported general problems in this domain suggests that courts should consider procedural changes to reduce these stressors.

Judges' concerns about personal safety and precautionary measures taken revealed an interesting pattern. The ratings of concern found were in some ways contradictory to the somewhat high prevalence of measures respondents reported adopting in response to safety threats, suggesting judges may have been hesitant to openly disclose personal concern about safety issues. Harris et al. ${ }^{67}$ discovered a similar phenomenon, finding that even though judges reported altering both personal and occupational behaviors after experiencing a safety-related event, many claimed not to have been affected by the threat of violence. This issue needs more study to discern if these findings represent reality, or if judges are simply not reporting accurately.

On the question of the relationship of perceptions of safety and stress, our results revealed considerable reason for concern. These results reinforce assertions regarding the importance of safety-related issues for the judiciary and the need to address these concerns ${ }^{68}$ so that the functioning of the judicial system is not negatively impacted.

The findings suggesting that women are either more susceptible to stress or are more open about reporting stress and safety concerns demand more study. If females are more affected by safety concerns and stress, then intervention efforts may benefit female judges by incorporating specific measures tailored to the needs of female judges into the design of the intervention. Alternatively, if these differences are the product of a self-report bias, male judges should be encouraged to more openly acknowledge their experiences of stress and seek help without fear of stigmatization since their female counterparts are already more likely to do so. This underscores the importance of a general attitudinal change discussed by Miller and colleagues, ${ }^{69}$ in which the judicial system would come to support stress interventions as a necessary and important part of the trial process.

These results from our exploratory research suggest that any stress or safety interventions should equally focus on the protection and well-being of all judges. The results should contribute to a broader understanding of the nature of judicial stress, providing insight to into individual differences associated with both experiences of stress and safety concerns. Our research focus emphasizes how maintaining a safe and secure environment is important not only for judges, but ultimately also for the proper functioning of the American trial system. We hope that the work reported herein will encourage others to pursue research in this important area of study.

A number of caveats were noted for the research reported herein, including especially the possibility of socially desirable responses, and the fact that our sample was not representative. These caveats notwithstanding, this study represents an expansion on the research on courtroom stress and safety in particular in relation to judicial perspective. Through the incorporation of new dependant measures, including clinical instruments, this study builds on previous research by allowing for a more detailed examination of the nature of the stress experienced by judges. Moreover, this study represents the first research effort integrating both judicial stress and safety, allowing for the examination of the relationship between two important factors encountered by members of the judiciary. This research also adds to previous studies of judicial stress by examining individual differences, more specifically gender and experience with a work-related stressful incident, and their relation to both perceptions of stress and safety.

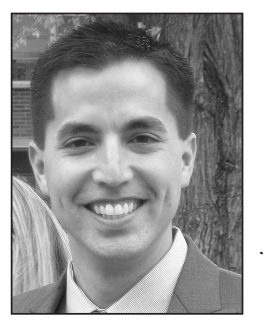

David M. Flores, Ph.D., is an affiliate of the Grant Sawyer Center for Justice Studies at the University of Nevada, Reno. His research interests include topics within the intersection of social science and law, with recent research projects involving various aspects of the American trial system, jury decision making, and issues related to the use of expert evidence. He earned his doctorate in social psychology, with an emphasis in psychology and law, through the interdisciplinary Ph.D. program in social psychology at the University of Nevada, Reno.
65. Miller, Courtroom Stress, supra note 8, at 9.

66. Id, at 9.

67. Harris, Judicial Workplace, supra note 10, at 50.

68. Chamberlain, Stress Triad, supra note 13; Don Hardenbergh, The

Future of Court Security and Judicial Safety, in FUTURE TRENDS IN
State CourTs (Tracy Peters, Neal Kauder, Chuck Campbell, \& Carol Flango, eds., 2005), available at http://www.ncsconline.org/ WC/Publications/Trends/2005/CtSecuJudclSafetyTrends2005.pdf. 69. Miller, Courtroom Stress, supra note 8 , at 8. 


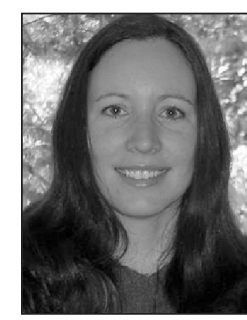

Monica K. Miller, J.D., Ph.D., is an associate professor at the University of Nevada, Reno. She has a split appointment between the interdisciplinary Ph.D. program in social psychology and the Criminal Justice Department. She has published numerous articles and books on various psych-legal topics, including stress and emotion in the legal system, how religion affects legal decision making, and jury decision making in general.

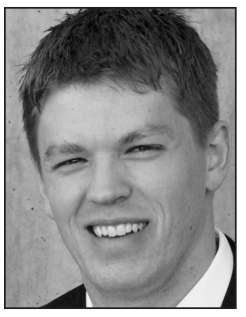

Jared Chamberlain, Ph.D., is an assistant professor at Argosy University in Phoenix, where he teaches courses in social psychology, research methods, and statistics. He is a graduate of the interdisciplinary Ph.D. program in social psychology at the University of Nevada, Reno. His research interests include celebrity influences in the legal system, stress among the judiciary, the legal rights and responsibilities of gay parents, and understanding attitudes toward gay-rights issues.

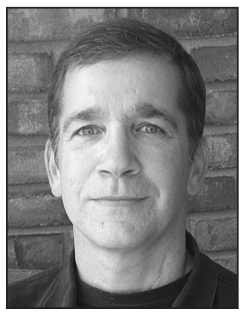

Brian H. Bornstein, Ph.D., M.L.S., is a professor of psychology and a courtesy professor of law at the University of Nebraska-Lincoln, where he has worked since 2000. His research interests include jury decision making, eyewitness testimony, and lay perceptions of justice. Bornstein is associate director of the UNL LawPsychology Program. He received a Ph.D. in psychology in 1991 from the University of Pennsylvania and a Master's degree in legal studies from the University of NebraskaLincoln in 2001. He has published numerous articles and has authored or edited six books, most recently God in the Courtroom: Religion's Role at Trial (with Monica K. Miller; Oxford, 2009) and Emotion and the Law: Psychological Perspectives (with Richard L. Wiener; Springer, 2010).

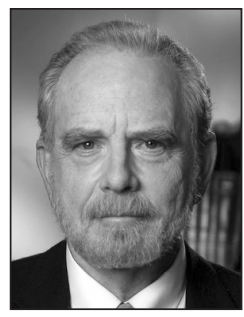

James T. Richardson, J.D., Ph.D., is director of the Grant Sawyer Center for Justice Studies at the University of Nevada, Reno. He is also director of the Judicial Studies graduate degree program for trial judges, a program offered in conjunction with the National Judicial College and the National Council of Juvenile and Family Court Judges, both of which are headquartered on the University campus. He received his Ph.D. in sociology in 1968 from Washington State University and his J.D. in 1986 from the Old College, Nevada School of Law. His research focuses on comparative studies of law and religion, the use of expert evidence in the legal system, and judicial stress.

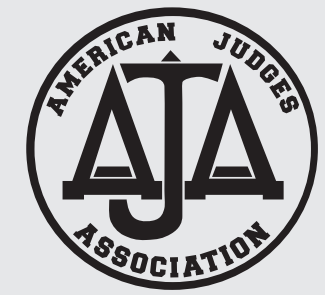

NOTICE FOR AMERICAN JUDGES ASSOCIATION MEMBERS

The newsletter of the American Judges Association, Benchmark, has been moved from print to electronic publication. If we have your email address on file, we will send Benchmark to you each time it is published. Benchmark is the official newsletter of the AJA, and it contains notice of AJA activities, elections, awards, and events. This move will help us make sure that you get timely notice of AJA information, and it will also help us in keeping AJA dues as low as possible.

You will continue to receive Court Review in the mail.

If you haven't provided your email address to the AJA, please send it to us at aja@ncsc.dni.us. We will use it only for authorized correspondence from the AJA. 